\title{
Evaluating the Flow Processes in Ultrafine-grained Materials at Elevated Temperatures
}

\author{
Megumi Kawasaki ${ }^{\mathrm{i}, \mathrm{b}}$, Terence G. Langdon ${ }^{\mathrm{a}, \mathrm{*} *}$ \\ ${ }^{a}$ Departments of Aerospace \& Mechanical Engineering and Materials Science, \\ University of Southern California, Los Angeles, CA 90089-1453, USA \\ ${ }^{\mathrm{b} D i v i s i o n}$ of Materials Science and Engineering, Hanyang University, 17 Haengdang-dong, \\ Seongdong-gu, Seoul 133-791, South Korea \\ 'Materials Research Group, Faculty of Engineering and the Environment, University of Southampton, \\ Southampton SO17 1BJ, UK
}

Received: August 29, 2012; Revised: September 25, 2012

\begin{abstract}
When polycrystalline materials are tested in tension at elevated temperatures, the flow mechanisms depend upon various parameters including the temperature of testing, the applied stress and the material grain size. The plotting of deformation mechanism maps is a procedure used widely in displaying and interpreting the creep properties of conventional coarse-grained metals but there have been few attempts to date to use this same procedure for ultrafine-grained and nanocrystalline materials produced through the application of severe plastic deformation (SPD). This report examines the potential for using deformation mechanism mapping for materials processed by SPD and presents examples for materials processed using equal-channel angular pressing and high-pressure torsion.
\end{abstract}

Keywords: deformation mechanism maps, equal-channel angular pressing, flow processes, high-pressure torsion, superplasticity

\section{Introduction}

The grain size of a polycrystalline material is an important parameter in determining the flow properties at elevated temperatures. Typically, when the grain size is large the material deforms through an intragranular dislocation process and there is no dependence on grain size but when the grain size is small additional flow processes become important such as grain boundary sliding, superplasticity and diffusion creep $^{1}$. In practice, it is well established that superplasticity becomes an important flow process only when the grain size is smaller than $\sim 10 \mu \mathrm{m}^{[2]}$. Using conventional thermo-mechanical processing, it is generally not possible to achieve grain sizes smaller than $\sim 1 \mu \mathrm{m}$ but new processing techniques have become available over the last two decades, primarily based on the application of severe plastic deformation (SPD) to bulk solids, and these processes provide opportunities for achieving ultrafine grain sizes within the submicrometer or even the nanometer range ${ }^{3,4}$. Typical SPD processing techniques currently in use are equal-channel angular pressing $(\mathrm{ECAP})^{5}$ and high-pressure torsion (HPT) ${ }^{6}$.

When a polycrystalline metal is tested in tension using a constant stress at elevated temperatures, the material deforms gradually in creep until ultimately it breaks. In practice, an understanding of the flow of metals under creep conditions is important when metals are used in high temperature applications. Specifically, an identification of the flow or rate-controlling mechanism becomes an important prerequisite in order to develop a predictive

*e-mail: langdon@usc.edu capability that may be used to estimate the strains attained over long periods of time.

Since creep is a diffusion-controlled process, it becomes important only at temperatures above $\sim 0.5 T_{m}$ where $T_{m}$ is the absolute melting temperature of the material. At these elevated temperatures, much of the creep flow generally occurs under steady-state conditions where the creep rate remains constant over a long period of time. Accordingly, much attention has been devoted to determining and identifying the flow processes that become important within the steady-state region.

In high temperature creep the steady-state strain rate, $\dot{\varepsilon}$, is generally expressed by a relationship of the form ${ }^{1}$

$\dot{\varepsilon}=\frac{A D G \mathrm{~b}}{k T}\left(\frac{\mathrm{b}}{d}\right)^{p}\left(\frac{\sigma}{G}\right)^{n}$

where $D$ is the appropriate diffusion coefficient $\left[=D_{0} \exp \right.$ $(-Q / R T)$, where $D_{\mathrm{o}}$ is a frequency factor, $Q$ is the activation energy, $R$ is the gas constant and $T$ is the absolute temperature], $G$ is the shear modulus, $\mathbf{b}$ is the Burgers vector, $k$ is Boltzmann's constant, $d$ is the grain size, $\sigma$ is the applied stress, $p$ and $n$ are the exponents of the inverse grain size and the stress, respectively, and $A$ is a dimensionless constant. It follows from Equation 1 that the creep mechanism is determined by the testing conditions of temperature and stress imposed on the material and by the initial grain size. Thus, the flow mechanisms are identified by using Equation 1 and determining the appropriate values for $n, p$ and $Q$. 
Over forty years ago it was proposed that creep mechanisms may be most readily identified through the construction of deformation mechanism maps in which, for a constant grain size, the normalized stress, $\sigma / G$, is plotted against the homologous temperature, $T / T_{m}$, from absolute zero to the melting temperature ${ }^{7}$. These maps contain contiguous fields that correspond to the dominance of a specific creep mechanism and generally strain rate contours are superimposed on the map to provide additional information on the creep rate. However, the maps are difficult to construct because the field boundaries are curved and extensive calculations are required to solve the relevant constitutive relationships for each deformation mechanism at a very large number of points in stress-temperature space. Alternative and simpler maps were suggested later including plotting the normalized grain size, $d / \mathbf{b}$, against the normalized stress, $\sigma / G$, at constant temperature ${ }^{8}$, plotting $d / \mathbf{b}$ against the inverse of the homologous temperature, $T_{m} / T$, at constant stress ${ }^{9}$ and plotting $\sigma / G$ against $T_{m} / T$ at constant grain size ${ }^{10}$. All of these alternative maps have an advantage because they are easy to construct for high temperature creep since the various field boundaries and strain rate contours appear as straight lines.

Although these various types of deformation mechanism map are well known in interpreting conventional creep mechanisms, there have been few attempts to date to apply the same approach to an analysis of the flow processes occurring in the ultrafine-grained materials produced by SPD processing. Accordingly, this paper addresses this deficiency by examining the procedures for constructing maps for materials processed by ECAP and HPT.

\section{A Deformation Mechanism Map for High-purity Aluminum}

Creep experiments were conducted on high-purity (99.99\%) aluminum after processing by ECAP, textures were determined using a high-pressure preferred orientation neutron time-of-flight diffractometer and these textures were shown to be in excellent agreement with the theoretical textures predicted using a visco-plastic self-consistent (VPSC) mode ${ }^{11}$. The aluminum was processed by ECAP for 4 passes using route $B_{C}$ where the sample is rotated by $90^{\circ}$ in the same sense between each consecutive pass through the ECAP $d_{i e}{ }^{12}$. Processing by ECAP refined the grain size from an initial value of $1 \mathrm{~mm}$ to an ultrafine grain size of $\sim 1.4 \mu \mathrm{m}$ and this grain size is consistent with microstructural results using electron backscatter diffraction (EBSD) showing the grains remain equiaxed with a size of $\sim 1.4 \mu \mathrm{m}$ up to 12 passes $^{13}$.

Tensile creep tests were conducted at $473 \mathrm{~K}$ over a range of stresses from 10 to $50 \mathrm{MPa}$ and the experimental results are shown in Figure 1 plotted as the steady-state creep rate against the applied stress. Results are shown for creep testing of both the ECAP samples and a sample in the as-received condition. All points lie along a single line with a slope given by a stress exponent of $n=5$. This value of $n$ suggests that the dominant rate-controlling mechanism is an intragranular process involving the glide and climb of dislocations.
A deformation mechanism map was constructed by plotting the normalized stress against the inverse of the homologous temperature for a grain size of $10 \mu \mathrm{m}$ as shown in Figure 2 where this grain size was selected because grain growth occurs at high temperatures and this is the anticipated grain size in high-purity aluminum processed by ECAP after heating to the creep testing temperature ${ }^{14}$. The map in Figure 2 depicts a number of domains corresponding to the different possible flow mechanisms. These domains were inserted using the appropriate constants for each

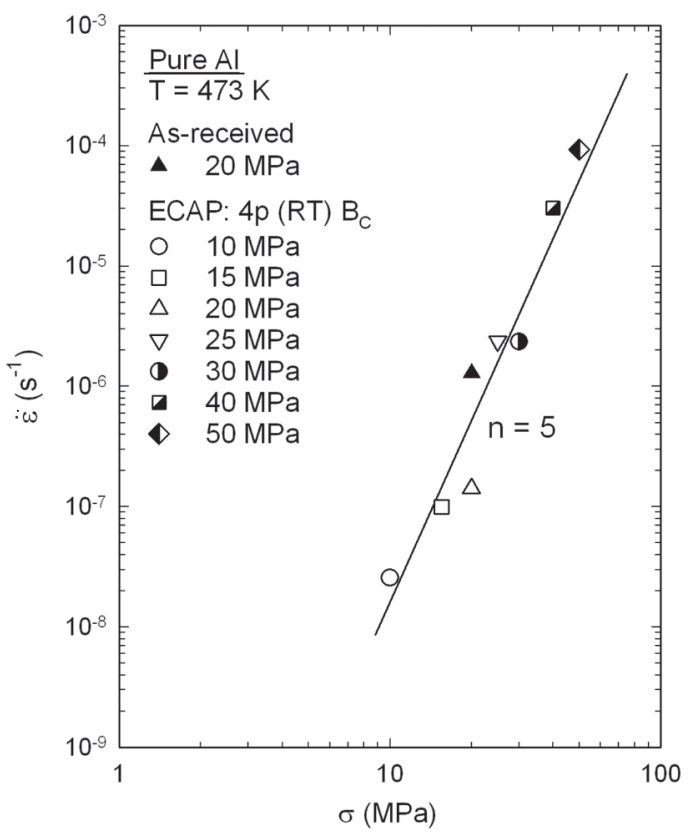

Figure 1. Creep rate versus stress for high-purity aluminum in the as-received condition and after processing by $\mathrm{ECAP}^{11}$.

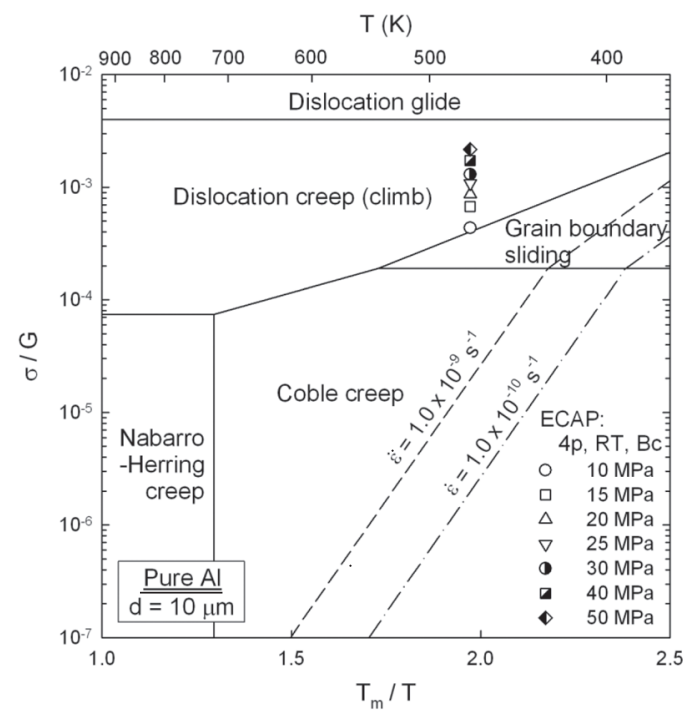

Figure 2. A deformation mechanism map of normalized stress versus the reciprocal of the homologous temperature for high-purity aluminum with a grain size of $10 \mu \mathrm{m}^{14}$. 
separate creep mechanism in Equation 1 and full details of the values used for the various parameters were given in earlier reports ${ }^{14,15}$. In Figure 2 the two areas labeled Nabarro-Herring creep $\mathrm{p}^{16,17}$ and Coble creep ${ }^{18}$ are based on the theoretical relationships developed for diffusional creep, the area labeled grain boundary sliding is based on the theoretical model for sliding in superplasticity ${ }^{19}$ where this mechanism has been shown to correspond closely to the flow behavior in materials processed by ECAP and exhibiting superplasticity, ${ }^{20}$ the field labeled dislocation creep (climb) is based on early data for power-law creep in high-purity aluminum ${ }^{10,21}$ and the upper transition to dislocation glide is based on a procedure developed for the construction of the earlier deformation mechanism maps ${ }^{7}$. The map also includes two strain rate contours for $1.0 \times 10^{-9}$ and $1.0 \times 10^{-10} \mathrm{~s}^{-1}$ where these rates are the lower limiting strain rates for laboratory experiments: other strain rate contours are easily inserted since the lines are parallel within each field and all strain rates are equally spaced on a map of this form.

The deformation mechanism map in Figure 2 shows field boundaries that delineate areas within which the specified creep mechanism is rate-controlling. Also included in Figure 2 are the datum points corresponding to the results presented in Figure 1 for the samples processed by ECAP where these points are plotted by using the applied stresses and the testing temperature. It is readily apparent that all of these points lie within the field for dislocation climb and this is consistent with the results in Figure 1 where the stress exponent is $n=5$. It is also possible to check the validity of Figure 2 by using the strain rates in Figure 1. Thus the lowest experimental strain rate for the test at a stress of $10 \mathrm{MPa}$ has a strain rate slightly faster than $\sim 10^{-8} \mathrm{~s}^{-1}$ and this is consistent with Figure 2 since the strain rate contours are displaced upwards for faster strain rates. This result confirms the ability to construct deformation mechanism maps that provide information on the predicted rate-controlling mechanisms over a wide range of testing conditions.

\section{A Deformation Mechanism Map for the Superplastic Zn-22\% Al Eutectoid Alloy}

Processing by SPD procedures provides an opportunity for achieving exceptionally small grains that are not easily attained using other methods. Since superplastic flow and high ductilities require a grain size of $<10 \mu \mathrm{m},{ }^{2}$ it is reasonable to anticipate that, provided these ultrafine grains are reasonably stable at elevated temperatures, materials processed by SPD will have the capability of exhibiting excellent superplastic properties. This trend was confirmed in an extensive review documenting more than 60 separate reports of superplastic elongations, corresponding to measured ductilities of $>500 \%$, in metals processed by $\mathrm{ECAP}^{22}$. More recently, there are also reports of high superplastic elongations in metals processed by HPT ${ }^{23,24}$.

Figure 3 shows an example of the excellent superplastic properties achieved in the $\mathrm{Zn}-22 \% \mathrm{Al}$ eutectoid alloy after processing by ECAP by pressing through 8 passes at $473 \mathrm{~K}$ using route $\mathrm{B}_{\mathrm{C}}{ }^{[25]}$. Tensile testing was conducted at $473 \mathrm{~K}$ over a range of strain rates from $1.0 \times 10^{-4}$ to $1.0 \mathrm{~s}^{-1}$ and the samples were pulled to failure. It is evident from Figure 3 that this material exhibits excellent superplastic properties with elongations up to $2230 \%$ at a strain rate of $1.0 \times 10^{-2} \mathrm{~s}^{-1}$. It is important to note that this strain rate corresponds to the occurrence of high strain rate superplasticity ${ }^{26}$. The results in Figure 3 are consistent with an early demonstration that superplastic flow occurs over about two orders of magnitude of strain rate under conditions designated region II and there are reductions in the elongations to failure at both slower and faster strain rates in regions I and III, respectively ${ }^{27}$. It is also apparent in Figure 3 that under optimum superplastic conditions the samples pull out without exhibiting the development of any necking within the gauge length: this is consistent with the basic requirement for superplastic flow ${ }^{28}$. For these experiments, the grain size was reduced to $\sim 0.8 \mu \mathrm{m}$ by ECAP.

A second example for the same alloy is shown in Figure 4 where the material was processed under HPT for 5 turns at room temperature (RT) using an applied pressure of 6.0 GPa and a rotation speed of $1 \mathrm{rpm}^{24}$. The tensile tests were also conducted at $473 \mathrm{~K}$ which is identical to the temperature used for the ECAP specimens in Figure 3. Again these samples show high tensile elongations with a maximum of $1800 \%$ at an imposed strain rate of $1.0 \times 10^{-1} \mathrm{~s}^{-1}$ and again

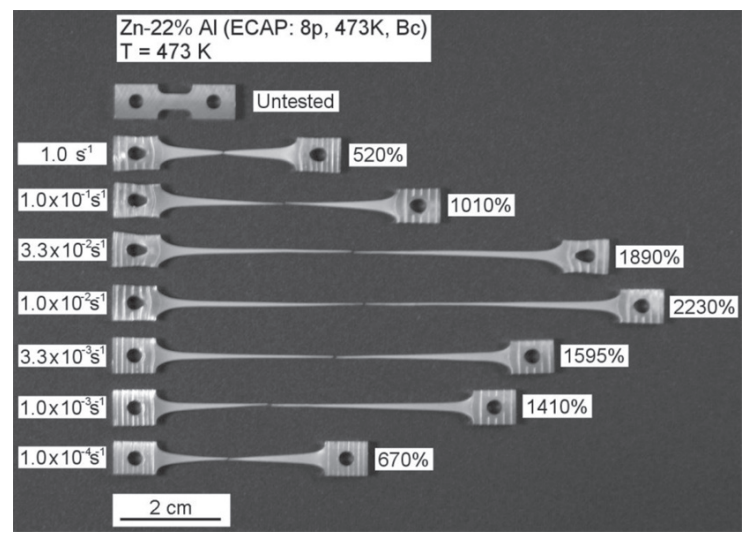

Figure 3. Superplastic flow in a $\mathrm{Zn}-22 \% \mathrm{Al}$ alloy after processing by ECAP and then testing at different strain rates at $473 \mathrm{~K}^{25}$.

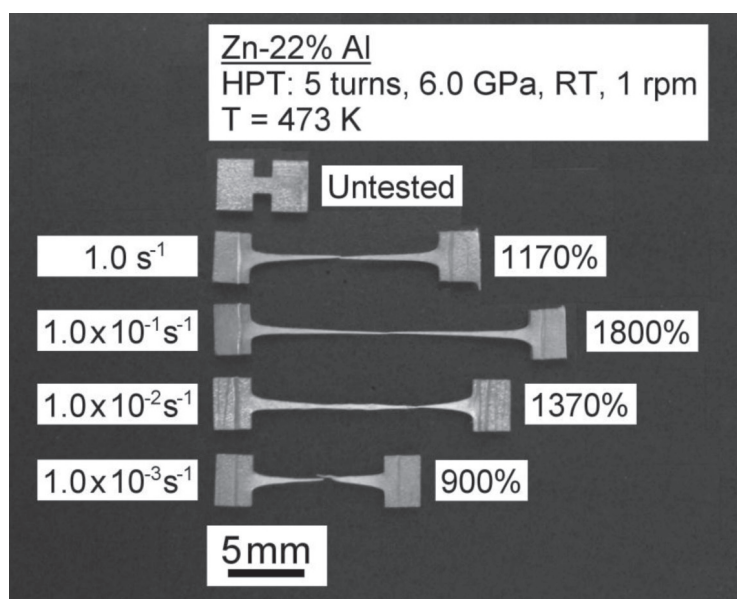

Figure 4. Superplastic flow in a $\mathrm{Zn}-22 \% \mathrm{Al}$ alloy after processing by HPT and then testing at different strain rates at $473 \mathrm{~K}^{24}$. 
there is a division into three regions of flow. The grain size of this alloy was estimated as $\sim 350 \mathrm{~nm}$ at the edges of the processed disks after 2 or more turns ${ }^{29}$.

There are two significant differences between Figures 3 and 4 . First, the maximum elongation occurs at a faster strain rate after HPT processing and this is consistent with the smaller grain size in HPT because, as noted in a very early report ${ }^{30}$, a reduction in grain size displaces the optimum ductility to faster strain rates. Second, the maximum elongation is higher in the sample processed by ECAP although the grain size is larger and this is due to the use of samples having different gauge lengths and cross-sectional areas ${ }^{31}$.

The testing temperature is $473 \mathrm{~K}$ for both the ECAP samples in Figure 3 and the HPT samples in Figure 4. Therefore, it is possible to construct a deformation mechanism map to include both sets of data. The result is shown in Figure 5 in the form of a map plotting the normalized grain size against the normalized stress for a constant temperature of $473 \mathrm{~K}$. This map was plotted using the theoretical models for Nabarro-Herring and Coble diffusion creep ${ }^{16-18}$ and fields were inserted for regions I, II and III based on experimental data for the $\mathrm{Zn}-22 \% \mathrm{Al}$ alloy obtained earlier using an alloy tested in an annealed condition without any SPD processing ${ }^{32,33}$. The datum points for the ECAP and HPT samples are superimposed on the map in Figure 5 and they lie correctly within the superplastic region II.

Figure 5 also includes a broken line labeled $d / \mathbf{b}=20(\sigma / G)^{-1}$ which represents the relationship for experimental measurements of the subgrain size in high temperature creep ${ }^{21}$ except that the size of the subgrains has been replaced by the grain size in the material, $d$. This line lies very close to the field boundary marking the intersection of regions II and III and it demonstrates, as noted earlier ${ }^{34}$, that the superplastic region II occurs at grain sizes which are sufficiently small that it is not possible to form any subgrains.

\section{A Deformation Mechanism Map for the Superplastic Pb-62\% Sn Eutectic Alloy}

The first attempt to construct a deformation mechanism map after SPD processing was for a $\mathrm{Pb}-62 \% \mathrm{Sn}$ eutectic alloy processed by $\mathrm{ECAP}^{35}$. This is a highly superplastic alloy exhibiting tensile elongations up to $>7000 \%{ }^{36}$. Later, a deformation mechanism map was constructed for a $\mathrm{Pb}-62 \%$ Sn alloy processed by ECAP at room temperature for 1 to 5 passes and the result is shown in Figure $6^{[37]}$. These specimens were processed using route $\mathrm{A}$ where the sample is not rotated between each consecutive pass ${ }^{12}$. Following ECAP, specimens were tested in tension at $423 \mathrm{~K}$ using strain rates from $1.0 \times 10^{-4}$ to $1.0 \times 10^{-1} \mathrm{~s}^{-1}$. The grain size of this alloy after ECAP processing was $\sim 5.5 \mu \mathrm{m}$ after 5 passes and the materials exhibited excellent superplastic properties with tensile elongations up to $>2000 \%$.

The map in Figure 6 employs the same approach as in the construction of Figure 5 with the theoretical relationships used for Nabarro-Herring and Coble diffusion creep $^{16-18}$ and earlier experimental data for the $\mathrm{Pb}-62 \% \mathrm{Sn}$ alloy for regions I, II and III ${ }^{34,38}$. The experimental points are included in Figure 6 and they lie correctly within the superplastic region II. The line delineating the lower limiting grain size for subgrain formation is also again in good agreement with the boundary between regions II and III.

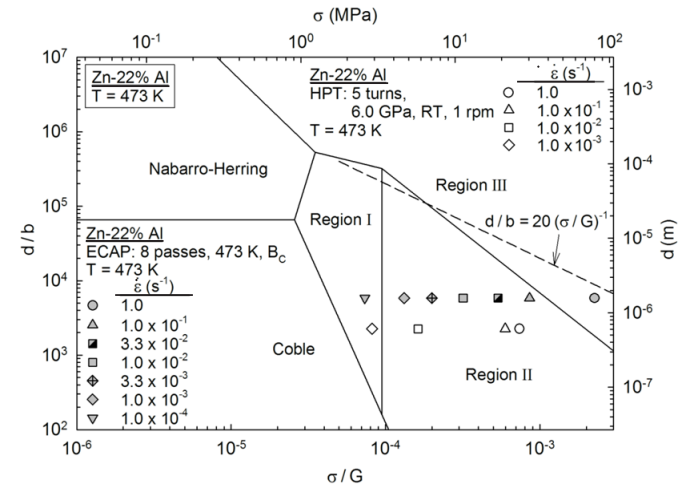

Figure 5. A deformation mechanism map of normalized grain size versus normalized stress for a $\mathrm{Zn}-22 \% \mathrm{Al}$ alloy tested at $473 \mathrm{~K}:{ }^{24}$ experimental points are shown after processing by $\mathrm{ECAP}^{25}$ and $\mathrm{HPT}^{24}$.

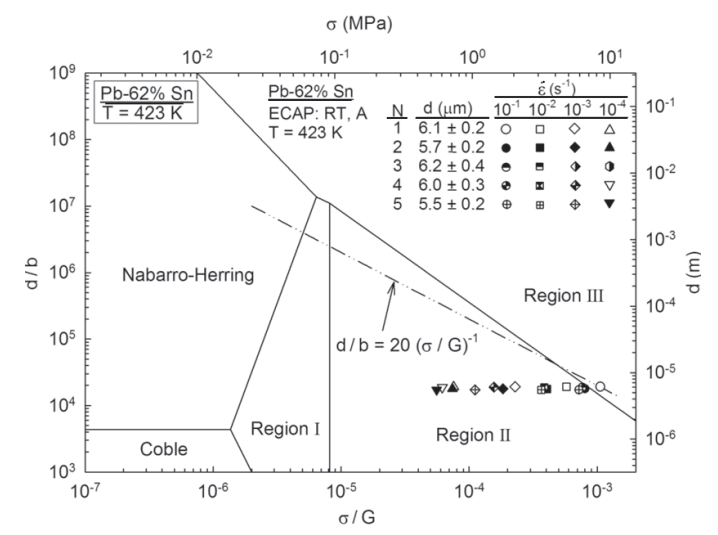

Figure 6. A deformation mechanism map of normalized grain size versus normalized stress for a $\mathrm{Pb}-62 \% \mathrm{Sn}$ alloy tested at $423 \mathrm{~K}^{37}$.

\section{Discussion}

The display of flow processes on deformation mechanism maps provides a useful tool for obtaining information both on the rate-controlling mechanisms under any selected experimental conditions and in providing a predictive tool that may be used to estimate the limitations and requirements associated with specific mechanisms. By plotting the maps in a simplified form, as in Figures 2, 5 and 6, the use of complex calculations is readily avoided and it is a simple process to prepare displays that provide meaningful information on the conditions associated with specific creep mechanisms.

In the maps presented in this report, the flow mechanisms are based on the use of Equation 1 with appropriate values for each of the terms within the constitutive relationship. These relationships are identical to those developed for the creep and plastic flow of conventional coarse-grained materials but they also work well for materials having grain sizes down to the submicrometer range (as in the $\mathrm{Zn}-22 \% \mathrm{Al}$ alloy processed by HPT to produce a grain size of $\sim 350 \mathrm{~nm}$ ).

It is important to note that it may be necessary to incorporate other mechanisms in the construction of maps for materials having exceptionally small grain sizes. ${ }^{39}$ For example, there is evidence for triple junction diffusion creep 
for materials having grain sizes smaller than $\sim 10 \mathrm{~nm}^{40}$. A general form of deformation mechanism map was proposed recently which included this mechanism ${ }^{41}$ but the present results demonstrate that the advent of any different flow processes is not important when the grain sizes are no smaller than in the submicrometer range. It is reasonable to conclude, therefore, that the present approach is valid at least for grain sizes down to $\sim 100 \mathrm{~nm}$.

\section{Summary and Conclusions}

Deformation mechanism maps are a valuable tool that may be used to identify and predict flow processes during high temperature deformation. These maps are used extensively in interpreting the creep behavior of coarse-grained materials but they are seldom used to examine the flow properties of ultrafine-grained materials.

\section{References}

1. Langdon TG. Identifying creep mechanisms in plastic flow. Zeitschrift für Metallkunde. 2006; 96:522-531.

2. Langdon TG. The mechanical properties of superplastic materials. Metallurgical Transactions A. 1982; 13A:689-701.

3. Valiev RZ, Estrin Y, Horita Z, Langdon TG, Zehetbauer MJ and Zhu YT. Producing bulk ultrafine-grained materials by severe plastic deformation. JOM. 2006; 58(4):33-39. http://dx.doi. org/10.1007/s11837-006-0213-7

4. Zhu Y, Valiev RZ, Langdon TG, Tsuji N and Lu K. Processing of nanostructured metals and alloys via plastic deformation. MRS Bulletin. 2010; 35:977-981. http://dx.doi.org/10.1557/ mrs2010.702

5. Valiev RZ and Langdon TG. Principles of equal-channel angular pressing as a processing tool for grain refinement. Progress in Materials Science. 2006; 51:881-981. http://dx.doi. org/10.1016/j.pmatsci.2006.02.003

6. Zhilyaev AP and Langdon TG. Using high-pressure torsion for metal processing: Fundamentals and applications. Progress in Materials Science. 2008; 53:893-979. http://dx.doi. org/10.1016/j.pmatsci.2008.03.002

7. Ashby MF. A first report on deformation-mechanism maps. Acta Metallurgica. 1972; 20:887-897. http://dx.doi. org/10.1016/0001-6160(72)90082-X

8. Mohamed FA and Langdon TG. Deformation mechanism maps based on grain size. Metallurgical Transactions. 1974; 5:23392345. http://dx.doi.org/10.1007/BF02644014

9. Langdon TG and Mohamed FA. A new type of deformation mechanism map for high-temperature creep. Materials Science and Engineering. 1978; 32:103-112. http://dx.doi. org/10.1016/0025-5416(78)90029-0

10. Langdon TG and Mohamed FA. A simple method of constructing an Ashby-type deformation mechanism map. Journal of Materials Science. 1978; 13:1282-1290. http:// dx.doi.org/10.1007/BF00544735

11. Kawasaki M, Beyerlein IJ, Vogel SC and Langdon TG. Characterization of creep properties and creep textures in pure aluminum processed by equal-channel angular pressing. Acta Materialia. 2008; 56:2307-2317. http://dx.doi.org/10.1016/j. actamat.2008.01.023
Examples of deformation mechanism maps are presented for three different materials processed by ECAP and HPT. These maps are relatively simple to construct and they provide useful information on the anticipated flow properties over a wide range of experimental conditions.

\section{Acknowledgements}

Participation at NANOMAT-2012 was made possible through award FAPESP\# 2011/51245-8 under a cooperation agreement with the University of Southampton. This work was supported in part by the National Science Foundation of the United States under Grant No. DMR-1160966 and in part by the European Research Council under ERC Grant Agreement No. 267464-SPDMETALS.
12. Furukawa M, Iwahashi Y, Horita Z, Nemoto M and Langdon TG. The shearing characteristics associated with equal-channel angular pressing. Materials Science and Engineering. 1998; A257:328-332.

13. Kawasaki M, Horita $\mathrm{Z}$ and Langdon TG. Microstructural evolution in high purity aluminum processed by ECAP. Materials Science and Engineering. 2009; A524:143-150.

14. Kawasaki M and Langdon TG. Characteristics of high temperature creep in pure aluminum processed by equal-channel angular pressing. Materials Science Forum. 2010; 638642:1965-1970. http://dx.doi.org/10.4028/www.scientific.net/ MSF.638-642.1965

15. Kawasaki M and Langdon TG. Using deformation mechanism maps to depict flow processes in superplastic ultrafine-grained materials. Journal of Materials Science. 2012; 47:7726-7734. http://dx.doi.org/10.1007/s10853-012-6487-y

16. Nabarro FRN. Deformation of crystals by the motion of single ions. In: Proceedings of the Conference on Strength of Solids; 1947; Bristol. London: The Physical Society; 1948. p. 75-90.

17. Herring C. Diffusional viscosity of a polycrystalline solid. Journal of Applied Physics. 1950; 21:437-445. http://dx.doi. org/10.1063/1.1699681

18. Coble RL. A Model for Boundary Diffusion Controlled Creep in Polycrystalline Materials. Journal of Applied Physics. 1963; 34:1679-1682. http://dx.doi. org/10.1063/1.1702656

19. Langdon TG. A unified approach to grain boundary sliding in creep and superplasticity. Acta Metallurgica et Materialia. 1994; 42:2437-2443. http://dx.doi. org/10.1016/0956-7151(94)90322-0

20. Kawasaki M, Balasubramanian N and Langdon TG. Flow mechanisms in ultrafine-grained metals with an emphasis on superplasticity. Materials Science and Engineering. 2011; A528:6624-6629.

21. Bird JE, Mukherjee AK and Dorn JE. Correlations between high-temperature creep behavior and structure. In: Brandon DG and Rosen A, editors. Quantitative Relation between Properties and Microstructure. Jerusalem: Israel Universities Press; 1969. p. 255-341. PMid:4311126. 
22. Kawasaki M and Langdon TG. Principles of superplasticity in ultrafine-grained materials. Journal of Materials Science. 2007; 42:1782-1796. http://dx.doi.org/10.1007/ s10853-006-0954-2

23. Horita Z, Langdon TG. Achieving exceptional superplasticity in a bulk aluminum alloy processed by high-pressure torsion. Scripta Materialia. 2008; 58:1029-1032. http://dx.doi. org/10.1016/j.scriptamat.2008.01.043

24. Kawasaki M and Langdon TG. Developing superplasticity and a deformation mechanism map for the $\mathrm{Zn}-\mathrm{Al}$ eutectoid alloy processed by high-pressure torsion. Materials Science and Engineering. 2011; A528:6140-6145.

25. Kawasaki M and Langdon TG. Grain boundary sliding in a superplastic zinc-aluminum alloy processed using severe plastic deformation. Materials Transactions. 2008; 49:84-89. http:// dx.doi.org/10.2320/matertrans.ME200720

26. Higashi K, Mabuchi M and Langdon TG. High-strain-rate superplasticity in metallic materials and the potential for ceramic materials. ISIJ International. 1996; 36:1423-1438. http://dx.doi.org/10.2355/isijinternational.36.1423

27. Ishikawa H, Mohamed FA and Langdon TG. The influence of strain rate on ductility in the superplastic $\mathrm{Zn}-22 \% \mathrm{Al}$ eutectoid. Philosophical Magazine. 1975; 32:1269-1271. http://dx.doi. org/10.1080/14786437508228105

28. Langdon TG. Fracture processes in superplastic flow. Metal Science. 1982; 16:175-183.

29. Kawasaki M, Ahn B and Langdon TG. Microstructural evolution in a two-phase alloy processed by high-pressure torsion. Acta Materialia. 2010; 58:919-930. http://dx.doi. org/10.1016/j.actamat.2009.10.007

30. Ma Y, Furukawa M, Horita Z, Nemoto M, Valiev RZ and Langdon TG. Significance of microstructural control for superplastic deformation and forming. Materials Transactions JIM. 1996; 37:336-339.

31. Zhao YH, Guo YZ, Wei Q, Topping TD, Dangelewicz AM, Zhu YT et al. Influence of specimen dimensions and strain measurement method on tensile stress-strain curves. Materials Science and Engineering. 2009; A525:68-77.
32. Mohamed FA and Langdon TG. Creep at low stress levels in the superplastic $\mathrm{Zn}-22 \%$ Al eutectoid. Acta Metallurgica. 1975; 23:117-124. http://dx.doi. org/10.1016/0001-6160(75)90076-0

33. Mohamed FA, Shei SA and Langdon TG. The activation energies associated with superplastic flow. Acta Metallurgica. 1975; 23:1443-1450. http://dx.doi. org/10.1016/0001-6160(75)90153-4

34. MohamedFA andLangdonTG. Deformation mechanismmaps for superplastic materials. Scripta Metallurgica. 1976; 10:759-762. http://dx.doi.org/10.1016/0036-9748(76)90358-6

35. Kawasaki M, Lee $\mathrm{S}$ and Langdon TG. Constructing a deformation mechanism map for a superplastic $\mathrm{Pb}-\mathrm{Sn}$ alloy processed by equal-channel angular pressing. Scripta Materialia. 2009; 61:963-966. http://dx.doi.org/10.1016/j. scriptamat.2009.08.001

36. Ma Y and Langdon TG. Factors influencing the exceptional ductility of a superplastic $\mathrm{Pb}-62$ pct $\mathrm{Sn}$ alloy. Metallurgical and Materials Transaction A. 1994; 25A:2309-2311.

37. Kawasaki M, Mendes AA, Sordi VL, Ferrante M and Langdon TG. Achieving superplastic properties in a $\mathrm{Pb}-\mathrm{Sn}$ eutectic alloy processed by equal-channel angular pressing. Journal of Materials Science. 2011; 46:155-160. http://dx.doi. org/10.1007/s10853-010-4889-2

38. Mohamed FA and Langdon TG. Creep behaviour in the superplastic $\mathrm{Pb}-62 \% \mathrm{Sn}$ eutectic. Philosophical Magazine. 1975; 32:697-709. http://dx.doi. org/10.1080/14786437508221614

39. Mohamed FA and Yang H. Deformation mechanisms in nanocrystalline materials. Metallugical and Materials Transactions A. 2010; 41A:823-837.

40. Wang N, Wang Z, Aust KT and Erb U. Effect of grain size on mechanical properties of nanocrystalline materials. Acta Metallurgica et Materialia. 1995; 43:519-528. http://dx.doi. org/10.1016/0956-7151(94)00253-E

41. Mohamed FA. Deformation mechanism maps for micro-grained, ultrafine-grained, and nano-grained materials. Materials Science and Engineering. 2011; A528:1431-1435. 